Excellence in Performing Arts Research

Volume 3

2016

\title{
The Interchanging Development of Sexuality: Laumann's Theory in LGBTQ Texts
}

Libby Jackson

This paper won the Award for Excellence in Undergraduate Research, 2015-16.

\section{Citation Elements}

Jackson, Libby (2016). The Interchanging Development of Sexuality: Laumann's Theory in LGBTQ Texts.

Excellence in Performing Arts Research Vol. 3 doi: 10.21038/epar.2016.0302. Retrieved from

https://oaks.kent.edu/epar/vol3/iss1/interchanging-development-sexuality-laumanns-theory-lgbtq-texts 


\begin{abstract}
Same-sex relations, despite their presence throughout history, have for the most part been misunderstood and are only recently beginning to be accepted. Even as these ideas have been explored dramatically, LGBTQ theatre that discusses such topics openly is still a largely new phenomenon. Nevertheless through analyzing these texts as they have developed throughout the centuries, their importance in contemporary repertoire is much more easily realized. Historically, views on how homosexuality manifested itself within the individual changed drastically. As new concepts and theories were introduced into society, these manifestations were understood differently both collectively and independently. Still, past views often lingered, muddling ideas on same-sex expression and its true countenance. In applying Edward Laumman's sexual theory to LGBTQ texts of different historical periods, the validity of the modern theory and its view on same-sex expression can more easily be recognized. In doing this, the complexity of sexual expression can be seen. Furthermore, it helps to not only explain society's views on homosexuality, but explains the individual's unique experience. Then in continuing to explore these ideas artistically, society can likewise continue to grow in such understanding.
\end{abstract}

\title{
Introduction
}

Throughout time and history, same-sex relations have always been present - though they have often been misunderstood or overlooked. In an attempt to better understand, such manners were deeply studied and eventually theorized in several ways. Same-sex relations have become conceptualized as both moral and immoral behaviors; mental illnesses; and intrinsic and possibly biological properties. And as these ideas, along with many others, came to manifest themselves within society, homosexuality in turn manifested itself within the individual in different ways. It was not until 1994 however, that such varying expressions became understood and stated, when Edward O. Laumann theorized the idea in a publishing of his studies on sexuality. It is then in looking at these studies that it can be understood how the meaning of homosexuality itself has changed throughout history.

As theatrical exploration coincided with this developing investigation, LGBTQ plays can very clearly show this change in perception. Finding texts with LGBTQ characters from as long ago as Elizabethan times, the written same-sex relations are presented much differently in comparison to the presentation of such in more contemporary plays. The relationships depicted within historical LGBTQ texts, such as Christopher Marlowe's Edward II and Martin Sherman's Bent, exhibit society's developing understanding of the three components of same-sex relations theorized by Edward Laumann, helping to illuminate the complexity of sexuality. Furthermore, it helps to enlighten the development of sexual identity as our society has come to understand it.

\section{The Kinsey Scale}

It was not until the $20^{\text {th }}$ century that most modern ideas regarding sexuality were developed. The first major revolutionary development in such ideas came when Alfred C. Kinsey, a sexologist at Indiana University, released a publication in 1948 on his conclusions from his sex research. After conducting interviews on individual's sexual histories, Kinsey found that many people did not fit neatly into the categories of heterosexual or homosexual. Rather, he and his colleagues found that for some, sexual behaviors were not consistent and changed with 
time. While his findings conceded most interviewees to be entirely heterosexual, many were indefinable, as they were not entirely homosexual either. In an attempt to explain these findings, the sexologist developed a scale to rank one's sexuality overall in regards to their entire sexual history. Beginning at zero, in which zero is exclusively heterosexual, the scale moves up to six, entirely homosexual, allowing each rank in between to describe a new degree of hetero/homosexuality ("Kinsey's Heterosexual-Homosexual Rating Scale").

\section{Flaws in the Kinsey Scale}

While the Kinsey Scale made great progress in the exploration of a more dynamic and varying sexuality, it did have its flaws. Most importantly, the scale was developed and operated with only the consideration of human behavior specifically in mind. Though it is true that behavior is an important factor in sexuality, behavior alone cannot encompass wholly one's entire disposition of attraction. Furthermore, the numerical scale in nature is unable to fully categorize each individualistic experience due to its confining ranking system. Subsequently, it was not until nearly half a century later that a theory was developed that maintained Kinsey's progress in destroying the previous restrictions of the purely heterosexual-homosexual labels, yet managed to explore sexuality fully, beyond just behavior.

\section{Laumann's Theory and Its Components}

It was with this that sociologist Edward Laumann crafted and published his own theory at the end of the $20^{\text {th }}$ century. Building off of Kinsey's own findings, Laumann's theory has defined same-sex relations to exist and present themselves in three ways including behavior, and goes on to consider desire, and/or identity. While all three components may manifest themselves together in an individual, it is also perfectly natural for one or two of the factors to exist and present themselves completely free of the others. Behavior consists of one's participation in sexual activity with another of the same sex. Within Laumann's study specifically, behavior is only noted when one has participated in such activity after the age of 18 . While behavior is most often coupled with one of the other two facets of homosexual expression, an example of behavior manifesting itself singularly is sex in prison. Sex in circumstances such as this are often the result of situation, by force or lure, due to the lack of heterosexual sex otherwise available. Desire then contends that one feels a want to have a sexual relation with another of the same sex. More simply put, desire is the equivalent to attraction or appeal for the same gender. The most common aspect of same-sex relations, desire can exhibit itself within one's fantasies or actively throughout life. It can occur sporadically, appear as a phase, or continue and dwell within an individual for years. Desire however, as often not acted upon, can exist merely within the mind. Finally, identity describes an individual who recognizes and classifies themselves as anything other than straight or heterosexual. Within this particular study, identity was considered present in anyone who deemed themselves as homosexual or bisexual. Laumann goes on to discuss how such combinations shift and merge and are experienced subjectively (Laumann et al. 292-320). Laumann et al. states, "All these motives, attractions, identifications, and behaviors vary over time and circumstances with respect to one another - that is, are dynamically changing features of an individual's sexual expression" (292). With this, Laumann is able to perfectly explain how these three components of homosexuality change with history and with the individual who experiences them. 


\section{Edward II}

While this theory was not conceived until 1994, LGBTQ characters dating back to the $16^{\text {th }}$ century still exemplify it well. This can be seen particularly well in Christopher Marlowe's history play Edward II. The piece tells the story of the king's reign as well as his inevitable demise. The play opens when King Edward II recalls his previously exiled lover, Piers Gaveston, to England. Upon his return, Edward II showers the man with material possessions as well as titles, causing him to treat the nobles of the court with an edge of superiority and bluntness. With this, the court becomes upset and convinces Edward that Gaveston must be exiled once more. However, Queen Isabella and her lover, Mortimer, stop the action in the hopes to more conveniently murder Gaveston on their own. The cease in action nevertheless angers the nobles once again, and Gaveston is murdered by two of the court. The death of his lover leads to Edward's distraction, providing Isabella and Mortimer the opportunity to travel to France to find allies to help fight and dethrone the king. Though the king has found new comfort and infatuation within a man by the name of Spencer, Edward II is forced to take refuge due to his lack of military skill and leadership as Isabella returns to battle. Despite his best attempts to hide, the king is captured, imprisoned, and finally murdered. As the play comes to a close, Prince Edward III discovers his mother's original plot against his father. Upon the discovery, Isabella is imprisoned, while Mortimer is put to death, leaving the young Edward III to take the throne (Marlowe I-V).

\section{The Elizabethan Era}

Edward II playwright Christopher Marlowe lived and wrote during the Elizabethan era (1564-1593) when sexual identity did not yet exist. On the contrary, same-sex relations were considered to be merely an action performed by an individual. Despite the conception of such as simply behavior however, same sex activity was punishable by hanging due to the reinstated sodomy laws of the time. Still, Edward II was not regarded as specifically offensive at the time because of its historical nature and evil depiction of Edward. Furthermore, the play emphasized the "justice" that would be brought to one who engaged in such activity (Keating). With this, it can be easily seen how the two facets of behavior and desire were recognized and treated at the time, both socially and individually, whilst identity remained nonexistent in the culture.

\section{Laumann's Components within Edward II}

These historical concepts on same-sex relations are easily seen within Edward II. A linked desire and behavior is presented clearly in the text between the main lovers of the piece. Edward and Gaveston both long for each other, and exhibit behavioral sexual expression with one another throughout the entirety of their relationship. This can first be seen as Marlowe opens his show with Gaveston expressing his yearning for Edward as he is recalled back to England. Gaveston says, "Sweet prince, I come. These, these thy amorous lines/ Might have enforced me to have swum from France,/ And, like Leander, gasped upon the sand,/ So thou wouldst smile and take me in thy arms" (Marlowe I.i.6-9). From this moment on, it is made transparently obvious to the audience that the men long for each other and their company in an intimate and romantic way. Edward's desire is then shown time and time again as he pines after his lover whilst he moves in and out of his life. And while on stage it can be played more innocently, 
Edward insists on a physical show of their relationship, calling for public passionate embraces when he scolds "Kiss not my hand" (Marlowe I.i.151). With this, the two continue to allow their sexual behavior and desire to be seen by the court. And along with the court, the audience is able to see through this relationship how these two aspects of same-sex attraction are manifested and intertwined.

Complexity of sexuality is proved even further with the show as behavior and desire are also presented separately as well. While same-sex behavior with removal from the other aspects of homosexuality is not shown within any of the acting characters, it is discussed. In fact, it is Edward's desire, rather than behavior, that causes such an uproar among the court nobles, as it keeps Gaveston from being dismissed as a whore and thus deemed unimportant (Stymeist). In truth, mere same-sex behavior was better understood, accepted, and released among the nobles at the time. This is shown when Mortimer exclaims, "The mightiest kings have had their minions:/ Great Alexander loved Hephestion;/ The conquering Hercules for Hylas wept;/ And for Patroclus stern Achilles drooped./ And not kings only, but the wisest men:/ The Roman Tully loved Octavius,/ Grave Socrates, wild Alcibiades" (Marlowe I.iv.390-396). In this way Marlowe shows how though behavior was still considered punishable, it was better understood than desire. The King however still displayed desire separate from behavior at the dismay of the court throughout the piece. This is best seen through the king after Gaveston's murder. As Edward recovers from the pain of losing him, he soon takes a strong interest in another man, Spencer. While it is not stated explicitly within the script, Edward's copious attachment to the man makes it clear that he has begun to desire him. Edward's desire is then projected once more for a third time towards the end of the piece on the character Lightborn. Meant to be the king's murderer, Edward spends his last moments with the man. As the king comes to face death, he pleads with Lightborn to stay by his side, an obvious show of his affection for the male. And it is this very plea for affection that thus constitutes Edward's demise. Despite both of these obvious displays of affection however, Edward does not act on such in any physical way. Through these many complicated relationships, it can then become clear that even in the $16^{\text {th }}$ century sexuality remained quite complex, as each of these two components of same-sex relations are displayed and revered in unique combinations.

\section{Non-Existent Identity}

Despite the intricacy of this sexual expression though, there is no concept of identity present within the text due to the time frame in which the script was written. As Laumann et al. writes, "Historians and anthropologists have shown that homosexuality as a category describing same-gender sexual desire and behavior is a relatively recent phenomenon (only about 100 years old) peculiar to the West" (290). Due to the lack of a concept of identity, Edward II is regarded simply as a sodomite. The lacking identity is thus shown best through Edward II's heteronormative behavior, as self-acceptance as gay was impossible at the time. This can be seen quite clearly in Edward's marriage to Isabella. Despite his returning same-sex desires and his behavior, Edward has gone on to marry and even father a child, as anything else was not only uncommon, but unknown at the time. Similarly, Gaveston becomes engaged to be wed to a woman, regardless of Gaveston's desires and behaviors. Furthermore, Gaveston and Edward's relationship is manifested as a friendship as opposed to a romantic relationship, perpetuating the lack of identity among the two. While it is made abundantly clear that the two are participating in a physical and intimate relationship with one another, the two perceive their relationship as 
nothing more than a camaraderie. For example, Edward continuously refers to Gaveston as his "brother" or "friend" throughout the show. This removal of romantic connection helps to establish the purely sexually motivated characteristics within the show necessary within desire and behavior. Through these actions, it not only becomes clear that identity is nonexistent, but it further separates desire and behavior from its linking - proving as Laumann stated, the possibility of any combination of such components to create a unique understanding of homosexuality.

\section{Bent}

Views and understanding on sexuality have complicated even further as time wore on and is evidenced through more contemporary theatre. One example may include Martin Sherman's 1979 play, Bent. The show tells the story of a gay man captured by the Nazis. After accidentally sleeping with a man recently ordered to death by Hitler, Max and his boyfriend Rudy are left on the run to escape the Nazi's imprisonment of anyone who is gay. While on the run, Max's closeted gay Uncle Freddy helps give Max papers to flee; however, Max refuses to leave without Rudy (though he claims not to love him) and as a result the two are captured. While on the train to the concentration camp, Rudy is beaten to death. Max, in an attempt to save his life as well as save his closeted view of himself, convinces the Nazis he is a Jew, rather than gay. Now in the camp, Max learns to confide in a man he met on the train, Horst. As the two talk, they fall in love and go on to make love despite their physical separation. It is then through Horst, that Max finally learns he must accept himself fully. Horst however is killed in the camp as entertainment for the guards. It is not until after this death that Max finally accepts himself and goes on to commit suicide in a direct rebellion against the cruel and non-understanding Nazis (Sherman).

\section{The Mid-1900s}

Playwright Sherman lived and wrote within the mid-1900s; specifically, during the 60s and 70s when ideas of sexual identity were first developing. Bent was written in 1979 as these ideas of identity were being brought to the forefront. Politically, activists argued for the identification of the gay community as unchanging and innate, in the hopes of creating a minority status to gain equal rights. Simultaneously seeing such ideas develop, the idea of identity is placed within Bent, as it had not been done previously, helping to explain and translate the concept and its emerging importance.

\section{Laumann's Components in Bent}

Though identity is largely intertwined with the other aspects of Laumann's theory, Bent exhibits all three components of the theory separately as well. To begin, behavior singularly is presented in the concentration camp, with Max and one of the Nazis. Accepting Max's sexual services as a bribe, one Nazi engages in same-sex activity. Paralleling Laumann's own example of sex in prison as solely behavioral, the Nazi can be assumed to remain free of both desire and identity, as he is putting others to death for exhibiting such qualities. Lone desire is then presented in Max and Rudy when they are on the run, but are unable to explore their relationship publicly and therefore physically. In the end of their journey, Max and Rudy are forced to remain unphysical as others constantly surround them. While the two cannot so much as share a kiss, 
they express their wish to be with one another constantly instead. This forced restraint is seen best when Max says, "If they see us...from the other tents...they're always looking...they could throw us out...for touching... we have to be careful...we have to be very careful" (Sherman). Meanwhile, Max has still not yet accepted himself as gay, and has not even accepted the fact that he loves Rudy. With this, Max exhibits desire free from behavior and identity, as the Nazis prevent him from displaying physical affection and his own self-loathing prevents identification. Identity unattached to the other facets is then shown through Horst. On the train, Horst explains to Max the workings of the concentration camp along with the meaning of the different symbols given to the prisoners. As he refers to his own pink triangle, meant to signify him as gay, he describes how such an identification is the worst within the camp. Despite this however, Horst wears his triangle with great pride as he has fully accepted himself and his sexual expression. At this point in the show, Horst has been held in a concentration camp for some time not specified, insinuating his lack of behavioral sexual relations. Furthermore, as he has just met Max, he has not yet begun to yearn for him in a sexual or romantic way. It is in this moment that the audience can briefly see sole identity, free from the entanglement of the other components.

Sherman allows the three components to be shown in conjunction with each other as well, enlightening sexuality's complexity. For example, Uncle Freddy displays both desire and behavior, though does not accept identity. More similarly, this character holds a historical view on same-sex attraction, insisting to Max throughout the show that identity is not something that needs to exist. Rather, he suggests, the indulgence of promiscuous behavior is more appropriate. This is seen best as he begs Max to leave Rudy, "Throwing it in everyone's face. No wonder they don't want anything to do with you. Why couldn't you have been quiet about it? Settled down, gotten married, paid for a few boys on the side. No one would have known" (Sherman). Reminiscent of Mortimer's speech on the nobles who participate in quiet affairs, this perfectly demonstrates how homosexuality apart from identity could be possible in more present times.

On the contrary, Max and Horst exhibit different combinations of the three components of sexuality in much different ways. Within the camp Horst is able to demonstrate the combination of desire and identity. As Horst has learned to accept his identity long ago, his intersection with desire merely follows suit as he falls in love with Max. Then, as the play progresses Max and Horst are able to learn to encompass all three components, just as society begins to understand all three exist and can connect. While Christopher Marlowe uses his characters in Edward II to explain same-sex desire at a time when it was still just beginning to be understood, Martin Sherman's Bent does the same for identity. It is thus through Horst that Sherman is able to explain how identity can uniquely interconnect with the other convolutions of same-sex expression as it is merely just a part of who one is. This is most aptly explained when Horst says, "There are queer Nazis. But what the hell. And queer saints. And queer mediocrities. Just people" (Sherman). It is then through these many combinations, complications, and explanations that Sherman so progressively demonstrates a fuller understanding of the same-sex relation, later to be theorized and explained by Laumann, as it manifests distinctively and naturally within the individual.

\section{Developing Identity}

The concept of identity however is still new and a struggle to accept and understand. Max's wrestling to understand and accept himself is well explained through the words of Laumann et al., as he detailed that "development of self-identification as homosexual or gay is a 
psychologically and socially complex state, something which, in this society, is achieved only over time, often with considerable personal struggle and self-doubt, not to mention social discomfort" (291). Max's continuous growth and struggle is well detailed in the text and can be seen when Max continually refuses love as a battered attempt to refuse his identity. The audience sees this best when he says, "Queers aren't meant to love. I know. I thought I loved someone once. He worked in my father's factory. My father paid him to go away. He went. Queers aren't meant to love" (Sherman). This, along with the fact that Max refuses to wear the pink triangle within the concentration camp, perfectly shows his inability to step out of his own self-loathing. Though Horst does eventually teach Max to accept himself fully, such acceptance leads him to suicide. His death thus wretchedly illustrates how even when one is developed enough to understand identity as valid, until society learns to accept the complexity of same-sex relations along with identity, inner-peace cannot be found.

\section{Conclusion}

All three of Laumann's components - behavior, desire, and identity — can be, have been, and will continue to be explored and interpreted within LGBTQ theatre. As the many characters within both of the shows are able to demonstrate the numerous and unique combinations of Laumann's components, each also demonstrates society's developing understanding of sexuality. Historically, dramatic literature could be used to explore sexuality beyond behavior and today, LGBTQ theatre continues to be used to explore sexuality as all three components are still being comprehended. The three components and their connectedness help not only to give an explanation to same-sex relations, but to the fluidity of sexuality overall. As these three components are continuously explored, sexual fluidity can become more accessible and thus better understood and accepted. And as such ideas become more commonplace and better comprehended, sexuality can continue to develop as a natural and open topic for all. 


\section{Works Cited}

Keating, Douglas. "In Marlowe's 'Edward Ii,' Homophobic Theme but Not Much Else."

Philadelphia Inquirer [Philadelphia] 3 Sept. 1993: Philly.com. Web. 7 Dec. 2015.

<http://articles.philly.com/1993-09-03/entertainment/25986897_1_gaveston-marloweedward-ii $>$.

"Kinsey's Heterosexual-Homosexual Rating Scale." The Kinsey Institute. Indiana University, Web. 29 Mar. 2016. <https://www.kinseyinstitute.org/research/publications/kinseyscale.php>.

Laumann, Edward, et al. The Social Organization of Sexuality. Chicago: U of Chicago, 1994. Marlowe, Christopher. Edward II. London: Nick Hern, 1997.

Sherman, Martin. Bent. New York City: Samuel French, 1979. Kindle File.

Stymeist, David. "Status, Sodomy, and the Theater in Marlowe's Edward II." Project Muse: Web. <https://muse.jhu.edu>. 